\title{
Patrimônio cultural e museus no Brasil: uma apreciação sob o ponto de vista da arqueologia
}

\section{Cultural heritage and museums in Brazil: an evaluation from an archaeological perspective}

\begin{abstract}
Resumo:
O presente texto busca discutir a importância dos museus de Arqueologia para a sociedade brasileira, evidenciando as transformações que lhe vêm sendo implementadas, a partir de questionamentos nascidos dentro do campo da Museologia, da Arqueologia e da História, como resposta às mudanças por que tem passado a sociedade brasileira nas últimas décadas. De forma a evidenciar tais transformações busca-se recorrer à revisão histórica dos diversos contextos político-culturais do país, destacando as transformações sociais em contexto pós-ditatorial. As políticas inclusivas e o surgimento de novos atores são, assim, relacionados aos questionamentos emergidos dos próprios campos científicos, possibilitando a compreensão do papel exercido por esses museus na contemporaneidade.
\end{abstract}

Palavras-chave: Arqueologia, Sociedade, Museologia

\footnotetext{
${ }^{1}$ Bacharel em História (1981), mestre em Antropologia Social (1986), doutor em Arqueologia (1990), pela USP, livre-docente em História (1996) e Professor Titular (2004) da Unicamp. Tem experiência na área de História e Arqueologia, com ênfase em História Antiga e Arqueologia Histórica, além de Latim, Grego, Cultura Judaica, Cristianismo, Religiosidades, Ambiente e Sociedade, Estudos Estratégicos, Turismo, Patrimônio, Relações de Gênero, Estudos Avançados.
} 


\begin{abstract}
This current text intends to discuss the importance of archeological museums within Brazilian society, making note of the transformations that have occurred within these institutionsdue to the questioning that has emanated from the fields of Museum Studies, Archaeology and History. This questioning has occurred in response to the changes that Brazilian society has experienced in the past few decades. In order to shed light on these transformations, we present a historical review of the diverse cultural and political contexts experienced by Brazil with emphasis on the social transformations experienced in the Post-Dictatorship period. New inclusive policies and theemergence of new protagonists are, in this way, linked to questioning that has emerged from within the various scientific disciplines themselves. This has made possible a new understanding of the roles that these museums play in contemporary society.
\end{abstract}

Key words: Archaeology, Society, Museum Studies

\title{
Introdução
}

Os estudos museais são um objeto complexo por inúmeras razões, não somente pelo fato dos museus estarem por definição na intersecção de uma variedade de áreas acadêmicas e profissionais (ALEXANDER, 1979). Os museus são logo à partida instituições de inúmeras práticas, abarcando desde a exposição até o armazenamento, incluindo conservação e guarda entre outras atividades (STRANSKY, 1980; FERNÁNDEZ, 2001). Além disso, há museus das mais variadas temáticas, desde as mais específicas, até as mais generalizantes, incluindo grandes e poderosas instituições e museus de pequeno porte, localizados nos mais afastados rincões do planeta (BRUNO, 2000). É quase uma tarefa impossível enumerar a enorme variedade de aspectos a que se referem os museus (MOUTINHO, 1994) e esta é a primeira razão para nos propormos a abordar este objeto sob o ponto de vista da Arqueologia.

Este é um ponto de vista limitado, considerando a grande variedade de museus existentes, mas ainda assim pode ser capaz de ampliar o nosso entendimento acerca dessas instituições (LEÓN, 1978; SCHAER, 1993): afinal de contas, até recentemente os museus coletavam cultura material, o objeto por excelência da Arqueologia 
(Chagas 1999). Museus de medicina ou de engenharia, somente para enumerar alguns dos tipos de museus especializados existentes, abrigam um conjunto de itens materiais relacionados com esses campos (DESVALLÉES, 1992;1994). Houve uma mudança substancial desse quadro nos últimos anos, quando a realidade virtual passa a ganhar espaço, mas ainda assim a cultura material é presente na maioria dos museus virtuais. Mais uma vez, minha formação específica na área de arqueologia indica que eu devo me concentrar em meu próprio território e há um aumento do interesse da arqueologia por questões museais (ORDÓÑEZ, AGUAROD, ERICE, 2005). Meu próprio entendimento da disciplina arqueológica é, assim, o caminho pelo qual desenvolvo o presente texto. Arqueologia é essencialmente interdisciplinar, incluindo biologia, geologia, e muitas outras áreas especializadas, mas eu a compreendo eminentemente como uma ciência social, como compreendida por Vere Gordon Childe (1956), e como um esforço humanístico, assim como propôs Johann Joachim Winckelmann muito tempo antes (1776; 2002). Eu também compreendo esse campo científico como um esforço social, conforme o mestre Peter Ucko (1995), não somente uma disciplina assentada na busca de fatos. É justamente sob essa conceituação que me proponho a abraçar a tarefa de descrever como museus, patrimônio cultural e engajamento social se interceptam no Brasil.

\section{A minha perspectiva}

Não há consenso interpretativo entre acadêmicos acerca de qualquer objeto, ainda que possa haver concordância em níveis gerais. Artigos e livros em co-autoria são sempre um compromisso de concordância entre as partes. Assim, meu primeiro passo será esclarecer meu ponto de vista específico sobre a problemática aqui abordada, meu próprio parti pris. A Ciência não é um objeto neutro: não existe nada parecido com uma descrição neutra de nenhum campo acadêmico ou de sua trajetória. A acumulação de conhecimento é, em última instância, uma ilusão, a despeito das revoluções científicas e das mudanças de mentalidade. Ambas estão 
relacionadas diretamente a mudanças sociais, de forma que o estudo de qualquer objeto científico é melhor compreendido quando acompanhado por um estudo das transformações sociais concernentes (PATTERSON 2001; HUDSON 1975). Se tal questão assim se dá de modo geral, ainda mais se confirma quando nos referimos ao Brasil, uma sociedade profundamente marcada por diferenças sociais, contradições e dificuldades. O Brasil é ainda hoje um dos países com mais desigualdades no mundo, e como consequência, marcado por conflitos sociais e violência. Dessa forma, torna-se necessário, em primeiro lugar, nos focarmos na realidade social brasileira, para somente depois retornarmos aos museus.

\section{“O Brasil não é para principiantes"}

Tom Jobim, o famoso compositor clássico e popular brasileiro, uma vez disse o que se lê acima, materializando a dificuldade em se compreender este país. Como explicar o Brasil em poucas linhas? Difícil tarefa, mais ainda assim compensadora. Primeiro, uma viagem pela história nos permite considerar a densidade de suas características. O Brasil foi colonizado pelos portugueses que vieram com uma mentalidade conquistadora, trazendo consigo hierarquia, patrocínio e relações patriarcais, as principais características de sua mentalidade. Esse ethos foi estudado por diferentes intelectuais, como Gilberto Freyre (1933), Sérgio Buarque de Hollanda (1936), Raimundo Faoro (1958) e Roberto Da Matta (1979), para nomear alguns dos mais renomados intelectuais advindos de variadas trajetórias acadêmicas e perspectivas. O resultado é a sociedade mais desigual, de acordo com a distribuição de renda, conforme atestado pelo índice de Gini. Não só isso, como se os índices econômicos fossem suficientes para consubstanciar toda uma sociedade. Conforme salientado por todos os teóricos sociais que acabamos de mencionar - a propósito, nenhum deles economistas - a sociedade brasileira é caracterizada por fortes relações pessoais, em uma complexa rede de conexões. Também é diversificada, miscigenada, e o resultado de intercruzamentos contínuos, biológicos, mas, sobretudo, culturais. A este respeito, o teórico social cubano Fernando Ortiz (1940) propôs um termo, transculturação, muito útil para compreender não só Cuba, mas também o Brasil, uma sociedade com raízes profundas em uma grande variedade de grupos étnicos; todos 
eles em um intrincado intercruzamento. A maioria da população do país resulta de uma mistura entre europeus, nativos e africanos, e o país tem vários milhões de pessoas de origem italiana, árabe, alemã, mas também russa e japonesa, para citar apenas alguns grupos, considerando a grande variedade de Etnias presentes no Brasil. Todas essas características afetaram o Patrimônio e os Museus, como veremos.

\section{Um breve panorama do Patrimônio e dos Museus no Brasil}

O Brasil como possessão portuguesa sofreu falta de centros culturais e instituições durante os primeiros três séculos de colonização, devido a várias razões, inclusive a percepção das elites portuguesas e locais de que a civilização estava no poder colonial, não nos trópicos. A transferência da corte portuguesa para o Rio de Janeiro, em 1808, foi um caso particular no estabelecimento da primeira e única capital imperial em uma antiga colônia, sendo o Brasil levado a ascender em breve a parte do Reino Unido de Portugal, Brasil e Algarves (a Parte sul de Portugal), em 1815. Como parte da vontade imperial, o Museu Real foi estabelecido já em 1818 (mais tarde renomeado como Museu Nacional, como ainda é hoje conhecido). Sem educação superior a não ser algumas escolas de direito a partir de 1827, é possível dizer que a vida intelectual começou no Brasil com um museu. Como argumentou Lúcio Menezes Ferreira (1999), o patrimônio, o museu e a arqueologia eram um empreendimento aristocrático, em sintonia com as tendências positivistas mais modernas em outros lugares, mas contribuindo para a manutenção da escravidão, da nobreza e da desigualdade social. O Patrimônio serviu à corte imperial do Rio de Janeiro para a promoção da identidade nacional durante o longo período imperial (1822-1889).

A república (1989-) mudaria o foco para novas preocupações patrimoniais, e novos museus, como mais notavelmente o Museu Paulista (1895), estudado novamente por Lúcio Menezes Ferreira (2010). Foi estabelecida como uma nova instituição acadêmica positivista, como parte da luta das elites para destruir e conquistar nativos. Reformado pelo centésimo aniversário da independência (1922) foi 
e ainda é um elogio das elites locais. A oligarquia de São Paulo, o estado capitalista mais dinâmico da nova República, inventou um heróico passado colonial, como bandeirantes míticos (literalmente detentores de bandeira) ou pioneiros que conquistaram o sertão (Funari 1994, 1997). O movimento levou à criação de uma série de interpretações materiais deste passado mítico, incluindo estátuas, fotos e muito mais, a maior parte ainda conosco hoje, embora tenham sofrido interferências posteriores. A influência desta posição foi desafiada, porém, pelo desaparecimento do governo oligárquico, em 1930, quando um novo período democrático e nacionalista levou primeiro a movimentos inclusivos, tendo entretanto se recrudescido, logo depois culminando em uma ditadura fascista (1937-1945) conhecida como Estado Novo (conforme estudado por POLONI, 2013). Durante esse período, foram estabelecidas diversas iniciativas patrimoniais com o objetivo de criar uma herança barroca colonial em Minas Gerais, bem como a legislação do patrimônio nacional, e o Patrimônio Brasileiro também foi criado. De certa forma, é possível dizer que as questões patrimoniais e os museus foram criados neste período, com consequências nos dias atuais.

A Democracia foi restabelecida na sequência da Segunda Guerra Mundial, como consequência de vários movimentos, incluindo a participação das tropas brasileiras ao lado dos aliados na Europa contra o Eixo. Mesmo que tenha sido muito instável e de alcance limitado, a democracia liberal trouxe uma série de mudanças na sociedade brasileira e depois no Patrimônio. As mulheres começaram a participar da vida social como nunca antes, os movimentos sociais estavam ativos, a exclusão social e as desigualdades foram desafiadas de várias maneiras. Neste contexto, os direitos e o patrimônio indígenas foram pela primeira vez incluídos na lista das demandas sociais. Graças a Paulo Duarte (1899-1984), um lutador humanista e da liberdade, uma lei que protege a herança indígena foi aprovada no Congresso e ainda é a única a proteger o patrimônio arqueológico (SOARES, FUNARI, 2013). Além disso, o patrimônio ampliou seu escopo e começou a incluir outras heranças não-elitistas e masculinas, mas todas essas transformações foram interrompidas no dia $1^{\circ}$ de Abril de 1964, quando os militares tomaram o poder, afastaram a oposição, exilaram várias pessoas, aprisionaram outras e iniciaram uma Ditadura que durou vinte e um anos.

Mesmo que o patrimônio não estivesse na vanguarda das preocupações dos militares, eles foram rápidos em promover sua própria compreensão do tema e para 
impedir outras percepções. Levou apenas alguns meses para que se criasse o chamado Programa Nacional de Pesquisas Arqueológicas, em Washington, DC, PRONAPA (1965-1970), seguido de um novo programa de cinco anos para a Bacia Amazônica, região considerada,no período, propensa a guerrilhas (PRONAPABA 1970-1975). O elo tradicional entre a Arqueologia imperialista e a espionagem não era difícil de se deduzir. O Patrimônio Brasileiro também foi submetido a novas tendências conservadoras (2002; 2003), incluindo sua articulação com a Autoridade Brasileira de Turismo (Embratur) recentemente criada. O Brasil deveria ser o país feliz, com belas praias e mulheres, disponíveis para o consumo, como estudou Louise Alfonso Prado (2014).

A mudança surgiu como resultado dos movimentos sociais e na sequência do desaparecimento das ditaduras em Portugal e na Espanha. Como resultado, em 1979 a anistia permitiu o retorno dos exilados, os partidos foram legalizados logo depois, as eleições para governadores estaduais, em 1982, permitiram a ascensão de governos democraticamente eleitos em vários importantes estados, em 1985 um civil é eleito para a presidência e, em 1988, uma nova constituição é aprovada. Todos esses movimentos levaram a várias mudanças no patrimônio e nos museus no Brasil, ainda que a transição para a democracia se baseasse na manutenção de ex-governantes e associados nas posições de poder (HAGOPIAN, 1990). Depois de várias décadas, essa ainda é a situação. No geral, no entanto, houve uma tendência de longo prazo para a inclusão social, a liberdade de expressão e o respeito pela diversidade. Neste período (1979 até o presente), leis foram promulgadas para proteger o meio ambiente e o patrimônio, a devolução do poder aos estados e cidades também levou a leis e regras adotadas pelos poderes locais. Além disso, os museus foram criados para incluir minorias e as instituições estabelecidas também foram afetadas pelas novas tendências democráticas. Isso será discutido nas seguintes seções deste artigo.

\section{Engajamento social, patrimônio cultural, arqueologia crítica e museus}

Desde o final da década de 1970, a liberdade e a democracia levaram ao engajamento social na academia e no gerenciamento ambiental e patrimonial. 
Antropólogos, historiadores e outros cientistas sociais voltaram-se para o diálogo com pessoas comuns, nativos, afro-brasileiros e outros grupos sociais, inclusive mulheres. Todas as pessoas excluídas passaram a ser gradualmente valorizadas e a história vista de baixo, bem como as estratégias contra-discursivas passaram a ser desenvolvidas. O patrimônio cultural, a arqueologia e os museus ficaram para trás, por razões diferentes, mas relacionadas. O patrimônio cultural logo foi abalado pela mudança, à medida que os quilombos eram declarados patrimônio nacional e os nativos eram protegidos, ainda que houvesse conflitos impostos pelo fato de que 0 patrimônio continuava controlado, em vários casos, por aqueles interessados em manter o status quo. Ainda assim, o patrimônio cultural foi beneficiado pela promulgação de legislação de proteção epel o reforço do trabalho de campo arqueológico, resgate e salvamento. Por outro lado, a proteção do patrimônio das elites foi garantida pela regra contínua das políticas do mercado, permitindo que as elites sejam responsáveis pelas fundações relacionadas ao patrimônio, museus e outros temas relacionados.

A arqueologia sofreu para se recuperar do domínio autoritário. A arqueologia está enraizada com os assuntos estatais, considerando que a pesquisa acadêmica depende do financiamento e da autorização. Isso significou que uma arqueologia livre e crítica se desenvolveu tarde. Os primeiros estudos arqueológicos críticos e sociais foram sobre uma compreensão humanista da arte rupestre (Niède Guidon 1991), quilombos (Carlos Magno Guimarães, Guimarães e Lana 1980) e Missões jesuítas e índios Guarani (Arno Kern, 1994), todos eles no início década de 1980. Demorou mais alguns anos para que se desenvolvesse um interesse maior nos quilombos, com Palmares (Funari 1999; 2003), o assentamento mais importante do século XVII, estudado no início da década de 1990 e depois com Canudos, outro sítio arqueológico emblemático estudado por Paulo Zanettini (1996) na mesma década. Canudos foi uma comunidade pobre destruída pelos militares no final do século XIX, submersa por uma barragem e depois estado já em tempos democráticos durante um período particular de seca. Na década de 1990, legislação específica foi estabelecida, obrigando a que todos os empreendimentos desenvolvimentistas, tais como construção de estradas, represas, ferrovias, aeroportos e outras construções edificadas devessem ser submetidas a salvamento arqueológico. Isso resultou no surgimento de atividades de CRM, como várias empresas arqueológicas privadas que atendem às novas injunções 
legais. Desde então, 95\% de todo o trabalho arqueológico no Brasil é realizado por essas empresas, beneficiadas pelo contexto democrático e pelas forças do mercado (Caldarelli 2008; Barcelos 2012). Nem todos os relatórios arqueológicos são realmente estudos acadêmicos, mas tem havido melhoria desse quadro ano após ano. $\mathrm{Na}$ década de 2000, o alcance e o envolvimento social foram consagrados pelas leis da Arqueologia Brasileira, de modo que, de maneira geral, ainda que recentemente, a arqueologia tem se envolvido continuamente com questões sociais.

Os museus ficaram para trás, como esperado. Os museus são instituições estatais e, por definição, conservadoras: mantêm tradições, concedem estabilidade e são bastiões de ordem (Tamanini 2000). Isso significa que os museus eram e ainda são preservadores das tradições, e muitas vezes desvinculados da sociedade, como um princípio de higiene. No entanto, mesmo aí, houve mudanças em duas direções (Primo, 1999). Vários museus tradicionais estabeleceram programas de atividades, no campo educacional e não somente (Morandino, Almeida e Valente 2009; Duarte Cândido 2013). Outros museus foram criados ex novo, como o Museu Afro-Brasileiro ou o Memorial da Resistência, para lidar com a ditadura e a repressão no Brasil, no contexto da recente legislação discricionária. Nos últimos anos, os museus mudaram de duas maneiras interligadas: por um lado, são cada vez mais inclusivos. Por outro lado, há uma crescente comercialização de tudo, incluindo artefatos e museus. Tudo está à venda, em uma era de destruição (Meskell 2002; González-Ruibal, 2008).

\section{O caso do envolvimento de comunidades locais, incluindo grupos com diversas origens étnicas e sociais, na gestão de museus}

A gestão de museus mudou significativamente desde o fim do governo autoritário no final da década de 1970 e novas instituições foram formadas para atender às novas demandas das comunidades locais, indígenas e uma multiplicidade de origens étnicas e sociais. Explorarei algumas experiências inovadoras relacionadas aos afro-brasileiros e às pessoas perseguidas sob regimes ditatoriais e mais algumas atividades, incluindo nativos e crianças em idade escolar. As pessoas de ascendência africana formam a maioria da população brasileira, mas foi apenas em 2004 que um 
museu afro-brasileiro foi instalado em São Paulo (Rodrigues 2012). Foi e ainda é liderado por um importante artista plástico africano-brasileiro, Emmanoel Araújo. Inclui coleções de africanos, escravos e trabalhadores do Brasil, religiosidade, história, narrativa memorial e artefatos artísticos. Na mesma linha e em período recente, um Memorial da Resistência foi estabelecido em 2002, em São Paulo, no prédio usado pela polícia política do Estado durante várias décadas (1940-1983), incluindo os dois períodos ditatoriais (1937-1945 e 1964-1985). Aborda a repressão política e os abusos aos direitos humanos no Brasil, não apenas no passado, mas também no presente (Neves, 2001). Ambos os museus são visitados por milhares de pessoas e incluem principalmente crianças em idade escolar.

Pela primeira vez, no final dos anos 2000 , os nativos foram autorizados a manter o material arqueológico e gerenciar seu próprio museu através do Instituto Étnico e Ambiental Xingu. A coleção arqueológica foi o resultado da promulgação de legislação ambiental e patrimonial em uma parceria, incluindo a Unicamp. Esta exposição inovadora controlada por índios conquistou o prestigiado Prêmio Rodrigo Melo Franco de Andrade de proteção patrimonial ${ }^{2}$. O mesmo ethos de inclusão social está presente no trabalho com alunos de baixa escolaridade em Campinas, patrocinados por financiamento do Conselho Nacional de Pesquisas Científicas (CNPq) disponibilizado para remunerar crianças do ensino médio para que estudem e lidem com o patrimônio arqueológico. Os alunos lidam com o patrimônio arqueológico e, graças a isso, eles se consideram incluídos pela primeira vez como seres humanos reais (Funari e Bezerra 2012). Isso está ligado à abordagem humanista estabelecida Paulo Duarte, ao fato de que Duarte foi marginalizado e perseguido, e ainda assim seu legado para esses jovens é a valorização dos seres humanos, independentemente de sua caracterização étnica, social e econômica.

\section{Tornando coleções e exposições de museus acessíveis e engajadoras para todos os públicos, garantindo uma participação mais diversificada em atividades museológicas}

\footnotetext{
${ }^{2}$ Dados discponíveis em: http://portal.iphan.gov.br/portal/baixaFcdAnexo.do?id=1028.
} 
Os singulares e recentes exemplos, descritos na seção anterior, nos levam a descobrir como tornar as coleções e exposições dos museus acessíveis e atraentes para uma variedade de públicos. A grande maioria dos museus brasileiros, incluindo, nomeadamente, as instituições de arqueologia, ainda são visitadas por poucas pessoas e também é verdade que o Museu é visto no Brasil como lugar de velharias. $\mathrm{Na}$ língua popular, a palavra museu é usada como uma expressão depreciativa, como em "coisa de museu". Dessa forma, os Museus enfrentam uma luta árdua para mudar práticas e percepções. Isso explica por que vários museus preferem ser nomeados como centros culturais ou memorials, evitando as conotações coloquiais da palavra museu. Os museus e todas as outras instituições similares coletam coleções, armazenam, exibem e tentam se envolver com uma grande variedade de públicos. Vários museus estabeleceram programas abrangentes de divulgação visando a diferentes públicos, como no caso da Pinacoteca ou Museu de Artes Visuais de São Paulo, com o objetivo de incluir pessoas cegas e outras necessidades especiais (Tojal 2009).

A principal tendência nos últimos anos tem sido o estabelecimento ou reforço dos departamentos de educação em museus que visam, antes de mais, a dirigir-se aos alunos que visitam essas instituições, como é o caso em vários grandes museus. Vários museus pequenos e municipais também têm surgido, geralmente freqüentados por alunos das escolas locais. Não é incomum que os jovens de cidades menores tenham visitado o museu local. O treinamento dos professores dessas escolas para atender a essas demandas nem sempre é fácil, mas ainda assim é um movimento democratizante que acontece em todo o país. A situação é provavelmente mais difícil nas grandes cidades, onde os moradores em contexto de favela compõem até um quinto da sua população e que, mesmo quando comparecem às exposições de museus podem se sentir alienados devido a várias razões,entre as quais a profunda divisão social mencionada anteriormente neste artigo. Além disso, vários museus históricos e arqueológicos tradicionais ainda conservam uma compreensão muito conservadora e até reacionária da história e da sociedade, baseada em elogios hierárquicos e de elite.

\section{Conclusão e perspectivas}


Os desafios não devem ser subestimados. A sociedade brasileira se desenvolveu no último meio século, as desigualdades sociais foram reduzidas, a liberdade e o respeito pela diversidade também ganharam força. Entretanto, muito ainda deve ser feito para que se alcance uma compreensão menos violenta, desigual e mais histórica do país. Os museus arqueológicos melhoraram muito e a luta pela democracia, pelos direitos humanos e pelo respeito pela liberdade contribuiu para melhorá-los. Ainda assim, a estrada à frente está aberta para todos aqueles que valorizam a democracia e que consideram que a arqueologia pode servir como uma ferramenta libertadora.

\section{Referências}

ALEXANDER, E. Museums in motion: na introduction to the history and functions of museums. Nashville:American Association for State and Local History, 1979.

Barcelos, A. Arqueologia e Patrimônio no Brasil, um dilema inacabado. In: Tempos Acadêmicos, 10, 2012, 4-25.

BRUNO, M.C.O. Museologia: a luta pela perseguição ao abandono. (tese de livre docência/ Universidade de São Paulo). USP: São Paulo, 2000.

Caldarelli, S. Arqueologia em grandes empreendimentos: a importância e o desafio de manter um controle de qualidade científica. In: Cadernos do Lepaarq, 5, 9/10, 2008, 35-63.

CHAGAS, M. Há uma gota de sangue em cada museu. (Cadernos de Sociomuseologia, 13). Lisboa: Universidade Lusófona de Humanidades e Tecnologias, 1999.

CHILDE, V. G. A short introduction to archaeology. London: Muller, 1956.

DAMATTA, R. Carnavais, malandros e heróis. Rio de Janeiro: Rocco, 1997 (1979), Carnivals, rogues and heroes, Notre Dame University Press, 1991.

DESVALLÉES, A. Vagues: une anthologie de la nouvelle museologie. Mâcon:Edition W,1992 (vol 1) e 1994 (vol 2). 
DUARTE CÂNDIDO, Manuelina Maria . Gestão de museus, um desafio contemporâneo: diagnóstico museológico e planejamento. v.1. 1. ed. Porto Alegre: Medianiz, 2013.

FAORO, R. Os donos do poder. 2.ed. Porto Alegre: Editora Globo, 1975. (1958)

FERNÁNDEZ, I. A. Museologia y museografia. Barcelona: Ediciones Del Serbal, 2001.

FERREIRA, L. M. . Território Primitivo: A Institucionalização da Arqueologia no Brasil (1870-1917). 1. ed. Porto Alegre: EDIPUCSRS, 2010.

FERREIRA, L. M. Vestígios de Civilização: O Instituto Histórico e Geográfico Brasileiro e a Construção da Arqueologia Imperial (18381870). In: Revista de História Regional, Ponta Grossa, v. 4, p. 9-36, 1999.

FREYRE, Gilberto. Casa-Grande \& Senzala. Editora Record: Rio de Janeiro, 1998 (1933).

FUNARI, P. P. A. . Dictatorship, democracy, and freedom of expression. In: International Journal of Historical Archaeology, Nova lorque, v. 7, n.3, p. 233-237, 2003.

FUNARI, P. P. A. El Mito Bandeirante: Élite Brasileña, Cultura Material e Identidad. In: Boletín de Antropología Americana, MÉXICO, v. 24, p. 110-122, 1997.

FUNARI, P. P. A. . Maroon, race and gender: Palmares material culture and social relations in a runaway settlement. In: P.P.A. Funari, M. Hall, S. Jones. (Org.). Historical Archaeology, Back from the edge. Londres: Routledge, 1999, v. , p. 308-327.

FUNARI, P. P. A. Rescuing Ordinary People's Culture: Museums, Material Culture And Education In Brazil. THE PRESENTED PAST, HERITAGE, MUSEUMS AND EDUCATION. LONDRES: ROUTLEDGE, 1994, v. , p. 120-136.

FUNARI, P. P. A; Bezerra, M. Public Archaeology in Latin America. In: Robin Skeates; Carol MacDvid; John Carman. (Org.). The Oxford Handbook of Public Archaeology. 1ed.Oxford: Oxford University Press, 2012, v. 1, p. 100-115.

FUNARI, P.P.A. Class interests in Brazilian archaeology. In: International Journal of Historical Archaeology, New York, v. 6, n.3, p. 209-216, 2002.

GONZÁLEZ-RUIBAL, A. Time to destroy, Current Anthropology, 49, 2, 2008. pp. 247-279. 
GUIDON, N. Peintures préhistoriques du Brasil; L'art rupestre du Piauí. Paris: Editions Recherches sur les Civilisations, 1991.

GUIDON, N. Peintures préhistoriques du Brasil; L'art rupestre du Piauí. Paris: Editions Recherches sur les Civilisations, 1991.

GUIMARÃES, C. M. ; LANNA, Ana L D . Arqueologia de Quilombos em Minas Gerais. In: Revista de Antropologia, v. 31, p. 23-28, 1980.

HAGOPIAN, F. "Democracy by Undemocratic Means"? Elites, Political Pacts, and Regime Transition in Brazil. In: Comparative Political Studies, July, 1990 vol. 23 no. 2 147-170.

HOLANDA, Sérgio Buarque de. Raízes do Brasil. Coleção Documentos Brasileiros. 19. ed. Prefácio de Antônio Cândido. Rio de Janeiro:José Olympio, 1987. (1936).

HUDSON, K. A Social History of Museums: what the visitors thougt. London: MacMilam,1975.

Kern, A.A. Utopias e missões jesuítas. Porto Alegre: Ed. UFRGS, 1994.

LÉON, A. El Museo: teoria,práxis y utopia. Madrid: Ediciones Cátedra,1978.

MARANDINO, M; ALMEIDA, A. M; VALENTE, M. E. A. (Org.) . Museu Lugar do Público. 1. ed. Rio de Janeiro: Fiocruz, 2009.

MENSCH, P. Objeto de estudo da Museologia. Rio de Janeiro: UNI-RIO/UFG, 1994.

MESKELL, L. Negative Heritage and Past Mastering in Archaeology. In: Anthropological Quarterly, 75, 3, 2002. pp. 557-574.

MOUTINHO, M. A Construção do Objeto Museológico. Lisboa: Universidade de Humanidades e Tecnologias, 1994.

NEVES, K.R.F. A potencialidade dos lugares de memória sob uma perspectiva museológica processual: um estudo de caso. $O$ Memorial da Resistência de São Paulo. Lisboa: Universidade Lusófona, 2011. Disponível em: http://www.museologiaportugal.net/files/upload/mestrados/katia_felipini.pdf.

ORDÓÑEZ, R.; AGUAROD, C.; ERICE, R. III Congreso Internacional sobre Musealización de yacimientos arqueológicos. Zaragoz:, Ayuntamento de Zaragoza, 2005.

ORTIZ, Fernando. Contrapunteo cubano del tabaco y el azúcar. Caracas: Biblioteca Ayacucho, 1978 (1940). 
PATTERSON, T. A Social History of Anthropology in the United States. Oxford: Berg, 2001.

POLONI, R. J. S. A Arqueologia e o encontro colonial: um passeio pelo mundo lusófono. In: I Semana de Arqueologia e Poder Anais da: I Semana de Arqueologia Arqueologia e Poder. Campinas: 2013.

PRADO, L. A. EMBRATUR: Formadora de imagens da nação brasileira. São Paulo: Annablume, 2014.

PRIMO, J. Museologia e Patrimônio: documentos fundamentais. (Cadernos de Sociomuseologia, 15). Lisboa: Universidade Lusófona de Humanidades e Tecnologias, 1999.

RODRIGUES, I.G.P. O museu e a identidade brasileira: Museu Afro Brasil, Biblioteca Latino-Americana de Cultura e Comunicação, 1. Disponível em: http://www.usp.br/celacc/ojs/index.php/blacc/article/viewFile/431/380.

SCHAER, R. L'Invention des Musées. Evreux: Gallimard, 1993.

SOARES, I.V.P.; FUNARI, P. P. A. Processo dos rinocerontes e outros: o acervo de Paulo Duarte e a importância de conhecer a verdade sobre dos acontecimentos na USP durante a Ditadura Militar. In: Revista Internacional de Direito e Cidadania, v. 2012, 2013. pp.183-192.

STRANSKý, Z. La Museologie:science, ou seulement travail pratique du musée ?. In: Museological Working Papers. Stockolm, n 1, 1980.

TAMANINI, E. Descobrir, Coletar, preservar: Aspectos da História dos Museus. In: Centro de Organização da Memória Sócio-Cultural do Oeste de Santa Catarina, Hilda Beatriz Dmitruk. (Org.). Educação Patrimonial e Fontes Históricas. v.12. 14ed.Chapecó/SC: Argos Editora, 2000. pp. 05-220.

TOJAL, Amanda Pinto da Fonseca. (Org.). Programa Educativo Públicos Especiais - Pinacoteca do Estado de São Paulo: esculturas selecionadas do acervo. São Paulo: , 2009. 12

UCKO, P. Introduction: archaeological interpretation in a world context. In: P J Ucko. (ed). Theory in Archaeology, 1-27. London: Routledge, 1995.

WINCKELMANN, J.J. Geschichte der Kunst des Alterthums (Text: erste Aufl. Dresden 1764, zweite Aufl. Wien 1776), hrsg. von Adolf H. Borbein, Thomas W. Gaethgens, Johannes Irmscher und Max Kunze, Mainz 2002.

ZANETTINI, P. et al. Arqueologia Histórica de Canudos. Salvador: Editora da UNEB, 1996. 
Treménória

em rede 